\title{
Assessment of postpartum depression among mothers following delivery in a rural based tertiary care centre, Nagpur, Maharashtra: A cross-sectional study
}

\author{
Shreya Khara ${ }^{1, *}$, Varsha Kose ${ }^{2}$ \\ ${ }^{1}$ MBBS Student , ${ }^{2}$ Associate Professor, Dept. of Obstetrics and Gynaecology, NKP Salve Institute of Medical Sciences and Lata \\ Mangeshkar Hospital, Hingna Road, Digdoh Hills, Nagpur, Maharashtra, India
}

*Corresponding Author:

Email: shreyak295@gmail.com

\begin{abstract}
Postpartum depression represents a considerable problem affecting women and their families. It may range from mild self limiting depression named postpartum blues to postnatal major depression and psychosis. By doing this study, many of the risk factors can be screened and we can provide intervention in proper time so as to reduce the morbidity. A cross sectional study was conducted in 100 postnatal women. Mothers were interviewed using Edinburgh Postnatal Depression Scale (EPDS) with cut off score of 12 . The result was analyzed by using the Chi-Square test. Out of 100 postnatal women included in the study, $13 \%$ women were found have EPDS score more than 12. Most of the patients were found to be in the age group of 20-30 years. It was also seen that most women who were educated up to high-school and belonged to joint families, were among the $13 \%$. The most commonly associated factors were low and average family income $(\mathrm{p}=0.013)$ and caesarean mode of delivery $(\mathrm{p}=0.003)$. The study implies that postpartum depression is highly prevalent and is mostly influenced by the family income and mode of delivery.
\end{abstract}

Keywords: Nervous, Postpartum blues, Insomnia, Depression, Anxiety, Guilt.

\section{Introduction}

Depression is the common psychiatric disorder that presents with depressed mood, loss of interest or pleasure, feelings of guilt or low self worth, disturbed sleep or appetite, low energy and poor concentration. These problems can become chronic or recurrent and lead to substantial impairments in an individual's ability to take care of his/ her everyday responsibilities. Postpartum depression represents a considerable problem affecting women and their families. Postnatal depression may range from mild self limiting depression named postpartum blues to postnatal major depression and psychosis. Most women are affected by mood symptoms in postpartum period (4-6 weeks after the childbirth). ${ }^{1}$

Recent study showed postnatal depression has a substantial impact on mother-baby interactions, longerterm emotional and cognitive development of the baby, especially when depression occurs in the first postnatal year of life. It is now considered a major health concern for women from diverse cultures. ${ }^{2}$ The first year of a child's life is crucial in terms of physical and psychological level, yet this is also the period when many mothers are susceptible to develop depressive disorders. By doing this study, many of the risk factors can be screened and we can provide intervention in proper time so as to reduce the morbidity.

\section{Aims and Objectives}

1. To find out prevalence of postpartum depression among mothers following delivery.

2. To study factors responsible for postpartum depression and significance of those factors among participants.

\section{Materials and Methods}

It was a cross-sectional study conducted in the Department of Obstetrics and Gynaecology and the Department of Paediatrics, NKP Salve Institute of Medical Sciences and Research Centre and Lata Mangeshkar Hospital, Nagpur after obtaining permission from institutional ethics committee. Mothers were interviewed using Edinburgh Postnatal Depression Scale (EPDS) $)^{3-4}$ with cut off score of 12 . Hundred postnatal women attending Gynaecology OPD for follow-up and Paediatrics OPD for immunization to their baby, upto 6 months post-delivery were interviewed. The study was conducted from August to September 2017. Mothers with history of delivery in the last six months were included in the study after taking informed consent. The Edinburgh Postnatal Depression Scale was used to assess the degree of postpartum depression among postnatal mothers.

The questionnaire was given to the participants and responses were noted down. Care was taken to avoid the possibility of the participant discussing her answers with others. The women were then classified according to their age, parity, literacy, monthly income, marital status, family structure, mode of delivery and obstetric outcome. The groups were compared on various sociodemographic and obstetric variables to determine risk factors associated with postpartum depression. The result was analyzed by using the Chi-Square test and the relationship and significance of the selected variables were found out. $\mathrm{p}<0.05$ was considered statistically significant. Frequency and percentage distribution will be used to assess the demographic variables regarding postpartum depression. The women 
who fulfilled the inclusion criteria were included in the study.

Inclusion Criteria: All the postnatal women beyond one month after delivery upto six months, who were willing to participate in the study, were included.

Exclusion Criteria: Participants unwilling to participate in the study, patients with history of known psychiatric disorder during or before the course of the pregnancy were excluded.

\section{Results}

In the study, 100 postnatal women who had visited the hospital and who fulfilled the inclusion criteria were included in the study. They were studied using the Edinburgh Postnatal Depression Scale for analysis of depression and significance of contributing factors. $13 \%$ women were found to be depressed from the scores of the test.

Table 1: Characteristics of the study sample and comparison between depressed and non-depressed women

\begin{tabular}{|l|l|c|c|c|c|}
\hline Parameter & Subgroup & $\begin{array}{c}\text { Depressed } \\
\text { Score }>\mathbf{1 2} \\
(\mathbf{n = 1 3})\end{array}$ & $\begin{array}{c}\text { Non } \\
\text { Depressed } \\
\text { Score }<\mathbf{1 2} \\
(\mathbf{n}=\mathbf{8 7})\end{array}$ & $\begin{array}{c}\text { Total } \\
(\mathbf{n = 1 0 0})\end{array}$ & Significance \\
\hline Age(yrs) & $<20$ & 0 & 1 & 1 & $\mathrm{p}=0.913$ \\
\hline & $20-25$ & 7 & 41 & 48 & \\
\hline & $25-30$ & 4 & 34 & 38 & \\
\hline & $>30$ & 2 & 11 & 13 & \\
\hline Education & Illiterate & 0 & 2 & 2 & $\mathrm{p}=0.192$ \\
\hline & Just Literate & 11 & 51 & 62 & \\
\hline & Graduate/PG & 2 & 34 & 36 & \\
\hline $\begin{array}{l}\text { Family } \\
\text { Structure }\end{array}$ & Joint & 7 & 54 & 61 & $\mathrm{p}=0.57$ \\
\hline & Nuclear & 6 & 33 & 39 & \\
\hline $\begin{array}{l}\text { Family } \\
\text { income }\end{array}$ & $<5000$ & 5 & 9 & 14 & $\mathrm{p}=0.013$ \\
\hline & $5000-10000$ & 7 & 51 & 58 & \\
\hline & $>15000$ & 1 & 27 & 28 & \\
\hline $\begin{array}{l}\text { Gender of } \\
\text { baby }\end{array}$ & Male & 6 & 37 & 43 & $\mathrm{p}=0.805$ \\
\hline & Female & 7 & 50 & 57 & \\
\hline $\begin{array}{l}\text { Mode of } \\
\text { Delivery }\end{array}$ & Vaginal & 0 & 37 & 37 & $\mathrm{p}=0.003$ \\
\hline & Caesarean & 13 & 50 & 63 & \\
\hline $\begin{array}{l}\text { Obstetric } \\
\text { Outcome }\end{array}$ & Healthy & 8 & 69 & 77 & $\mathrm{p}=0.155$ \\
\hline & Sick & 5 & 18 & 23 & \\
\hline
\end{tabular}

Maximum number of depressed women were found in the age group of 20-25 years of age (7\%). $2 \%$ women were illiterate, $62 \%$ women were just literate, and $36 \%$ women had done either their graduation or PG. $61 \%$ women lived in joint families. $14 \%$ women had their monthly income less that 5000 rupees, $58 \%$ women had their monthly income from 5000-10000 rupees, and the rest had family monthly income more than 15000 rupees. The table shows association between family income and prevalence of depression. Also, mode of delivery is associated with depression in this study (Table 1).

\section{Discussion}

Among the most important contributors to the global burden of disease and disability are mental health problems. ${ }^{5}$ Incidence of postpartum depression in this test was $13 \%$, a test conducted by Ghosh $\mathrm{A}$ et $\mathrm{al}^{6}$ showed $25 \%$ prevalence and one conducted by Patel V et $\mathrm{al}^{7}$ shows $23 \%$ prevalence. As the sample taken is from tertiary care sector rather than the community, it is more likely to be representative of the rural population who have chances of having medical follow up and other facilities.

The significant association between EPDS scores and depression and anxiety during current pregnancy is similar to studies done elsewhere. ${ }^{8}$ In present study, we found that female baby (57\%) and caesarean delivery (63\%) were risk factors contributing to depression. Significant risk factors $(p<0.05)$ are observed to be family income $(\mathrm{p}=0.013)$ and mode of delivery $(p=0.003)$. Age, education, family structure, gender of the baby and obstetric outcome are not statistically 
significant among the females of this study, which is in contrast to a similar study conducted in Oman. ${ }^{9}$

In this test, caesarean section deliveries were found to be a significant factor to case postpartum depression. Similar results were obtained in another study, which showed $1 / 3^{\text {rd }}$ women who had caesarean section deliveries had postpartum depression.

\section{Conclusion}

The implication of this study wherein it was observed that postpartum depression is highly prevalent and is associated with a lot of risk factors, is that attention should be paid to counseling antenatal women for the challenges ahead. A pregnant woman should be talked to about what it would be like with the coming of the baby, and also the husband and the family should be counseled to take care of the mother. An effort to remove gender bias in their minds should be made, as it can reduce depression rates due to this reason. The antenatal women should be told about modes of delivery and also why caesarean has to be opted for in certain cases due to medical indications, which cannot be ignored to have a normal vaginal delivery. The factor of family income can be dealt with, by introducing cost effective plans for the family so that taking care of the child doesn't seem like a burden to them. Social support can be strengthened to decrease cases of depression.

\section{References}

1. Mohamed HAS, Jaber MMA, Al-Hamadani Z, Khmour HY, Al Lenjawi BA, Schlogl JM. Prevalence of postnatal depression and associated risk factors among South Asian mothers living in a newly developing country. Asian J Pharm Clin Res 2016;9(6):57-61.

2. Dhande N, Khapre M, , Nayak S, Mudey A. Assessment of postnatal depression among mothers following delivery in rural area of Wardha district: A cross sectional study. Innovative Journal of Medical and Health Science 2014;4:53-5.

3. Cox JL, Holden JM, Sagovsky R. Detection of postnatal depression: Development of the 10-item Edinburgh Postnatal Depression Scale. British Journal of Psychiatry 1987;150:782-86.

4. Wisner KL, Parry BL, Piontek CM. Postpartum depression. N Engl J Med 2002;347(3):194-99.

5. Afifi M. Gender differences in mental health. Singapore Med J 2007;48(5):385-91.

6. Ghosh A, Goswami S. Evaluation of postpartum depression in a Tertiary Hospital. J Obstet Gynaecol India 2011 Oct;61(5):528-30.

7. Patel V, Rodrigues M, DeSouza N. Gender, poverty and postnatal depression: A study of mothers in Goa, India, 2002. Am J Psychiatry 2002 Jan;159(1):43-7.

8. Andersson L, Sundstrom-Poromaa I, Wulff M. Depression and anxiety during pregnancy and six months postpartum: A follow-up study. Acta Obstet Gynecol Scand 2006;85(8):937-44.

9. Al Hinai FI, Al Hinai SS. Prospective study on prevalence and risk factors of postpartum depression in Al-Dakhliya Governorate in Oman. Oman Med J 2014;29(3):198-202. 